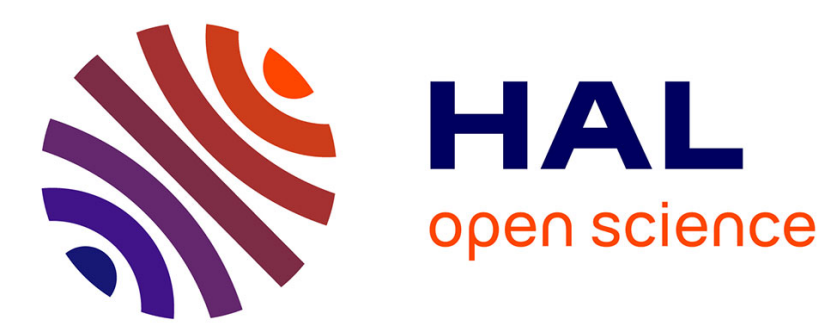

\title{
DOPANT INCORPORATION DURING NONEQUILIBRIUM SOLIDIFICATION
}

\author{
C. White
}

\section{To cite this version:}

C. White. DOPANT INCORPORATION DURING NONEQUILIBRIUM SOLIDIFICATION. Journal de Physique Colloques, 1983, 44 (C5), pp.C5-145-C5-155. 10.1051/jphyscol:1983524 . jpa00223105

\section{HAL Id: jpa-00223105 https://hal.science/jpa-00223105}

Submitted on 1 Jan 1983

HAL is a multi-disciplinary open access archive for the deposit and dissemination of scientific research documents, whether they are published or not. The documents may come from teaching and research institutions in France or abroad, or from public or private research centers.
L'archive ouverte pluridisciplinaire HAL, est destinée au dépôt et à la diffusion de documents scientifiques de niveau recherche, publiés ou non, émanant des établissements d'enseignement et de recherche français ou étrangers, des laboratoires publics ou privés. 


\title{
DOPANT INCORPORATION DURING NONEQUILIBRIUM SOLIDIFICATION
}

\author{
C.W. White
}

Solid State Division, Oak Ridge National Laboratory, Oak Ridge, Tennessee 37850 , U.S.A.

Abstract - Systematic studies of dopant incorporation into silicon during rapid solidification are reviewed, including measurements of interface temperatures and thermal gradients during solidification. Mechanisms limiting dopant incorporation at high concentrations are discussed. Melting of the surface of thin amorphous layers on a crystalline substrate is shown to take place at anomously low laser energy densities.

\section{I - INTRODUCTION}

In pulsed-laser annealing of silicon, the deposition of laser energy into the nearsurface regions leads to melting, followed by liquid-phase-epitaxial regrowth from the substrate /1-5/. Several studies /6-10/ have shown that implanted or deposited Group III, IV, or V impurities can be incorporated into substitutional sites in the silicon lattice as a result of pulsed laser annealing, even when the dopant concentration greatly exceeds the equilibrium solubility limit. During solidification, the velocity /11/ of the interface is several meters/sec and recrystallization of the melted region occurs under conditions that are far from equilibrium. Here we review some of the systematic studies of dopant (Group III, IV, or V) incorporation in silicon as a result of pulsed-laser annealing. At low concentrations, dopant profiles after laser annealing can be compared to model calculations of dopant redistribution by liquid phase diffusion $/ 6 /$ in order to determine the distribution coefficients from the liquid $\left(k^{\prime}\right)$. At high concentrations there is a limit $\left(c^{\max }\right)$ to dopant incorporation into substitutional lattice sites $/ 6 /$. The mechanisms which limit dopant incorporation will be discussed as well as the dependence of $k^{\prime}$ and cmax on crystal orientation. Measurements /12,13/ of interface temperatures and thermal gradients during solidification will be discussed as well as measurements of anomously low thresholds for melting in thin amorphous silicon films.

\section{II - EXPERIMENTAL}

Group III, IV, or V impurities were implanted into both (100) and (111) Si to doses in the range of $1015-1017 / \mathrm{cm}^{2}$. The implant energies were chosen to give a projected range of $2800 \AA$. Laser annealing was carried out in air using either a pulsed ruby $\left(6934 \AA, 12 \times 10^{-9} \mathrm{~s}\right)$ or pulsed XeCl laser ( $3080 \AA$, trapezoidal pulse shape, $235 \mathrm{~ns}$ full width at half maximum). Analys is of the implanted samples was carried out using RBS-ion channeling measurements to determine the dopant profiles and substitutional concentrations as a function of depth. Selected crystals were examined by transmission electron microscopy (TEM) to determine the microstructure in the nearsurface region.

\section{III - DOPANT INCORPORATION AT LOW CONCENTRATIONS}

For Group III, IV, or V dopants at low concentrations, the dopant is trapped into substitutional lattice sites as a resuit of pulsed-laser annealing in the absence of any cell formation or dopant precipitation. In these cases, the interfacial

* Operated by Union Carbide Corporation under contract $W-7405-e n g-26$ with the U.S. Department of Energy. 


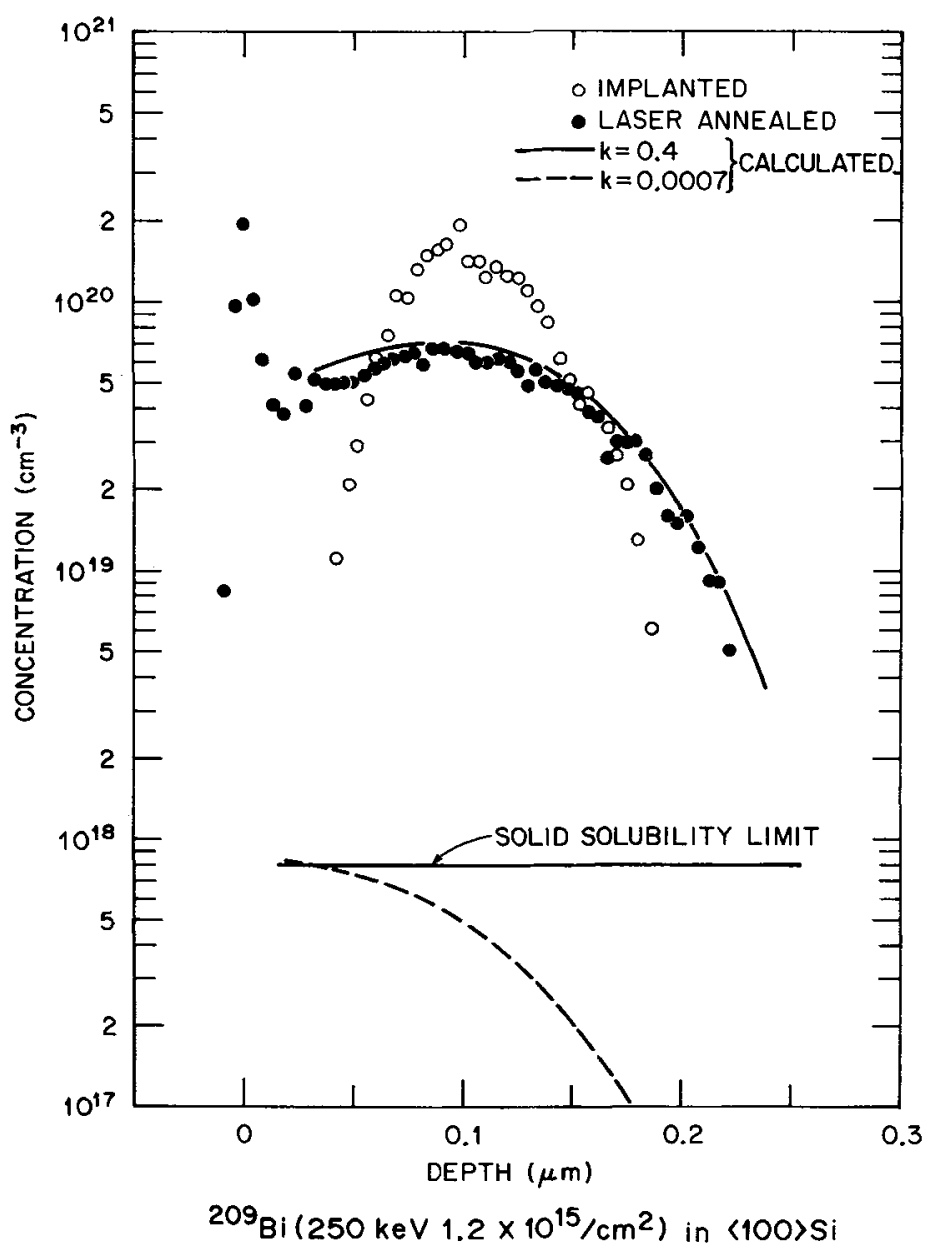

Fig. 1 - Dopant profiles for $209_{\mathrm{Bi}}\left(250 \mathrm{KeV}, 1.1 \times 10^{15} / \mathrm{cm}^{2}\right)$ compared to model calculations. From Ref. 6.

distribution coefficient (defined as $k^{\prime}=C_{S} / C_{L}$ where $C_{S}$ and $C_{L}$ are dopant concentrations in the solid and liquid phase at the interface) can be determined by comparing measured dopant profiles after laser annealing to model calculations for dopant redistribution by liquid-phase diffusion during solidification $/ 6 /$. In the calculations $k^{\prime}$ is treated as a fitting parameter and the best fit value for ${ }^{\prime}$ ' during solidification is determined by least squares analysis. Figure 1 shows an example for the case of $209_{\mathrm{Bi}}$ in (100) $\mathrm{Si}$. Approximately $15 \%$ of the implanted $\mathrm{Bi}$ zone refines to the surface during laser annealing, but that remaining in the bulk is substitutional in the regrown lattice even though the concentration exceeds the solubility limit by almost two orders of magnitude. The dopant profile can be fit with a value for $k^{\prime}=0.4$, which is much higher than the equilibrium value ( $7 \mathrm{x}$ $\left.10^{-4}\right)$. If solidification occurred under conditions of local equilibrium at the interface, the dotted profile would result and essentially all of the Bi would have zone refined to the surface. The large departure from conditions of local equilibrium at the interface is brought about by the very rapid regrowth velocity achieved during pulsed laser annealing $(V \sim 4.5 \mathrm{~m} / \mathrm{s}$ in the case of $\mathrm{Fig} .1)$. 
TABLE I

Comparison of distribution coefficients under equilibrium $\left(k_{0}\right)$ and laser annealed ( $\left.k^{\prime}\right)$ regrowth conditions.

\begin{tabular}{cll}
\hline Dopant & \multicolumn{1}{c}{$k_{0}$} & $k^{\prime}$ \\
\hline B & 0.80 & 1.0 \\
P & 0.35 & 1.0 \\
As & 0.30 & 1.0 \\
Sb & 0.023 & 0.7 \\
Ga & 0.008 & 0.2 \\
In & 0.0004 & 0.15 \\
Bi & 0.0007 & 0.4 \\
\hline
\end{tabular}

Table I summarizes / 9 / values for $k^{\prime}$ determined as described above for several impurities in silicon compared to equilibrium values $\left(k_{0}\right)$. Values for $k^{\prime}$ were determined at a growth velocity of $4.5 \mathrm{~m} / \mathrm{s}$ except in the cases of $B, P$, and $\mathrm{Sb}$ where a velocity of $2.7 \mathrm{~m} / \mathrm{s}$ was used. In every case $k^{\prime}>k_{0}$ which reflects the nonequilibrium nature of this high speed liquid-phase-epitaxial regrowth process. The increased values for $k^{\prime}$ relative to $k_{0}$ demonstrate that at these velocities solute atoms do not exchange a sufficient number of times across the interface to establish their equilibrium concentrations in the solid and liquid phases before being permanently incorporated into the solid. This process is referred to as solute trapping.

\section{IV - DEPENDENCE ON GROWTH VELOCITY}

Values for $k$ ' depend on growth velocity /14-16/ as demonstrated in Fig. 2 . Growth velocities of $1.5,4.5$, and $6.0 \mathrm{~m} / \mathrm{s}$ were achieved by ruby 1 aser annealing with the substrate held at $650 \mathrm{~K}, 300 \mathrm{~K}$, and $100 \mathrm{~K}$ respectively. At the lowest velocity $255 \%$ of the $B i$ is zone refined to the surface and the value determined for $k^{\prime}$ is 0.10 . The dependence of $k^{\prime}$ on growth velocity demonstrated in Fig. 2 is expected because as $v \rightarrow 0, k^{\prime} \rightarrow k_{0}$. A dependence of $k^{\prime}$ on growth velocity has been reported for the case of In in silicon $/ 17 /$, and a similar dependence should be observable for all Group III, IV, and V impurities in silicon.

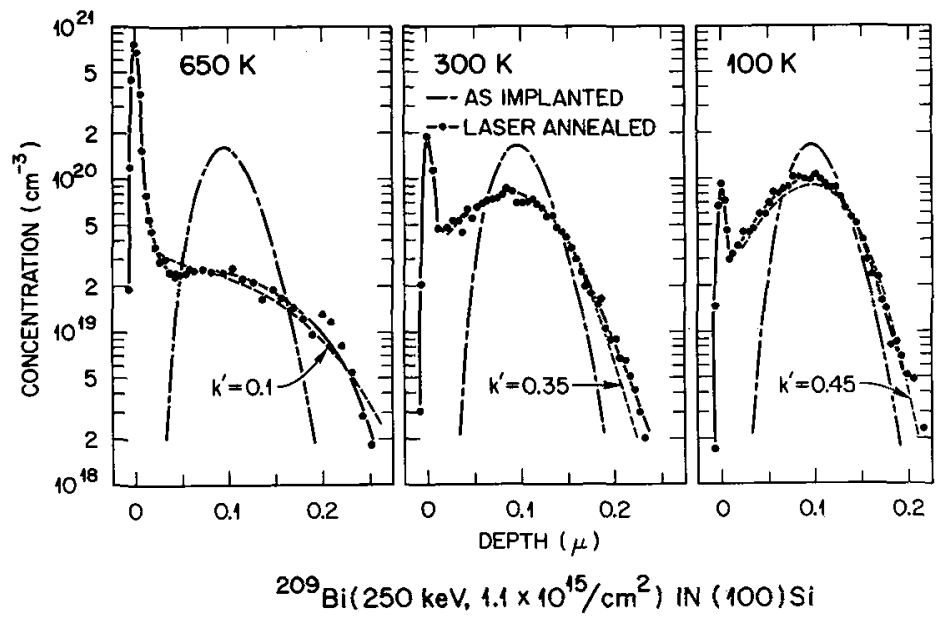

Fig. 2 - Profiles for 209 Bi (250 KeV, $1.1 \times 1015 / \mathrm{cm}^{2}$ ) in (100) Si ruby laser annealed at different temperatures. From Ref. 16 . 


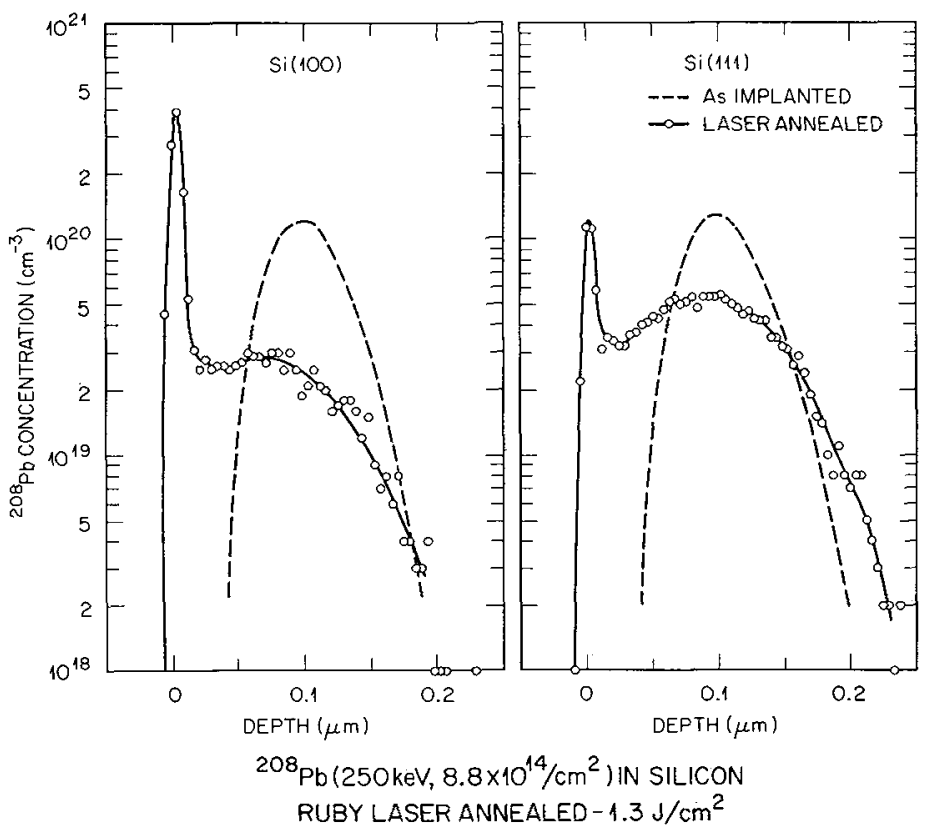

Fig. 3 - Profiles of 208pb in (100) and (111) Si following laser annealing.

\section{$\checkmark$ - DEPENDENCE ON CRYSTAL ORIENTATION}

In certain velocity ranges, the value for $k^{\prime}$ is dependent on crystal orientation /18/. An example is shown in Fig. 3 for the case of $208 \mathrm{~Pb}$ in (100) and (111) Si. The jmplanted crystals were laser annealed under identical conditions (ruby, 1.3 $\mathrm{J} / \mathrm{cm}^{2}, 12 \times 10^{-9} \mathrm{~s}, \mathrm{v} \sim 4.5 \mathrm{~m} / \mathrm{s}$ ) but considerably more $\mathrm{Pb}$ is retained in the bulk of the (111) crystal. This implies that the value for $k^{\prime}$ is greater in the (111) case even though the growth velocity is the same. A dependence of $k^{\prime}$ on crystal orientation has been observed in the case of $\mathrm{Bi}, \mathrm{In}, \mathrm{Ga}, \mathrm{Sn}$, and $\mathrm{Pb}$. The reported /17/ velocity and orientation dependence for In in silicon is shown in Fig. 4. Over the entire velocity range investigated, the value for $k^{\prime}$ is larger in the (1i1) case.

The dependence of $k^{\prime}$ on crystal orientation has been attributed to a larger interfacial undercooling on the (111) surface, compared to the (100) surface $/ 19 /$. As discussed in Ref. 20, growth velocity depends on the fraction of sites available for crystallization and the interfacial undercooling. For the (111) surface, the fraction of sites available for crystallization is less than that on the (100) surface. Consequently, the interfacial undercooling must be greater on the (111) surface in order to have the same growth velocity. Estimates indicate that interfacial undercoolings up to several hundred degrees might be expected $/ 19 /$. Using time resolved $x$-ray diffraction techniques, it has become possible to measure interface temperatures and thermal gradients during rapid solidification $/ 12,13 /$. The results of these measurements will be discussed in the next section.

\section{VI - MEASUREMENTS OF INTERFACE TEMPERATURES AND THERMAL GRADIENTS DURING RAPID SOLIDIFICATION}

Interface temperatures and thermal gradients during laser annealing can be determined on the nanosecond time scale from time resolved Bragg x-ray diffraction measurements of the near-surface strain profiles in the crystal /12,13/. For these measurements, one uses single pulses of x-rays from a synchrotron source, synchronized with the firing of the laser, to measure extended Bragg scattering resulting 


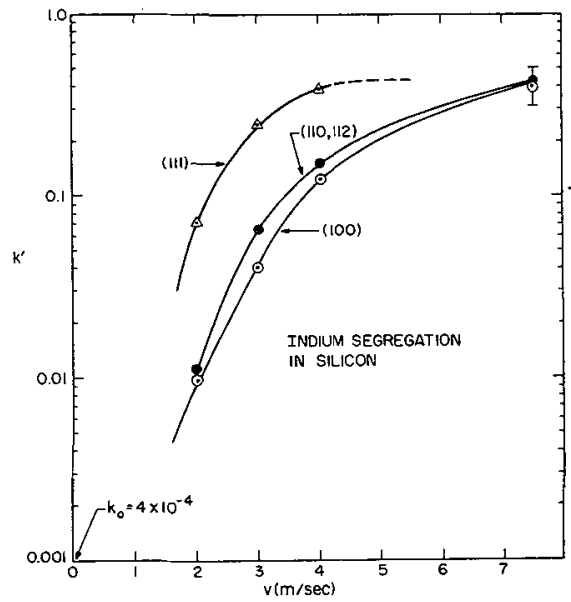

Fig. 4 - Dependence of $k^{\prime}$ on growth velocity and crystal orientation for In in silicon. From Ref. 17.

from thermal expansion in the near-surface region of the crystal. The firing of the 7 aser and the pulse of $x$-rays from the synchrotron are synchronized so that the laser light hits the crystal surface a predetermined time before the burst of $x$-rays. The time resolved $x$-ray diffraction measurements give directly the strain profiles in the near-surface region at a given time after the firing of the laser. Temperature profiles are determined from the thermal expansion analysis of the near-surface strain profiles.

Figure 5 shows Bragg x-ray scattering profiles near the (111) reflection on (111) oriented silicon measured at $20 \mathrm{~ns}, 55 \mathrm{~ns}$, and $155 \mathrm{~ns}$ following a ruby laser pulse of $1.5 \mathrm{~J} / \mathrm{cm}^{2}$. The $x$-ray scattering intensity resulting from the laser pulse ranges out to $\sim 450 \mathrm{~s}$ for the $20 \mathrm{~ns}$ and $55 \mathrm{~ns}$ cases, but only to $2375 \mathrm{~s}$ for the $155 \mathrm{~ns}$ case. This implies a lower temperature at $155 \mathrm{~ns}$ and the greater scattering intensity implies a shallower thermal gradient at this time. The temperature profiles in the crystalline part of the sample corresponding to the same delay times are shown in Fig. 6. In this figure, depth is measured from the liquid-solid interface during melting and solidification, and from the crystal surface after solidification is complete. At 20 and 55 ns the temperature reaches the melting point of silicon to within the uncertainty of measurements $\left( \pm 75^{\circ} \mathrm{C}\right)$. At $20 \mathrm{~ns}$ the melt front is penetrating into the crystal while at 55 ns solidification of the melted region is taking place. These results show that superheating of the solid during melting and interfacial undercooling during recrystallization are less than $75^{\circ} \mathrm{C}$, for the laser conditions used. For the results shown in Figs. 5 and 6 , recrystallization of the melted region is complete at $100 \mathrm{~ns}$ (as determined from measurements of the time resolved optical reflectivity). This accounts for the fact that the surface

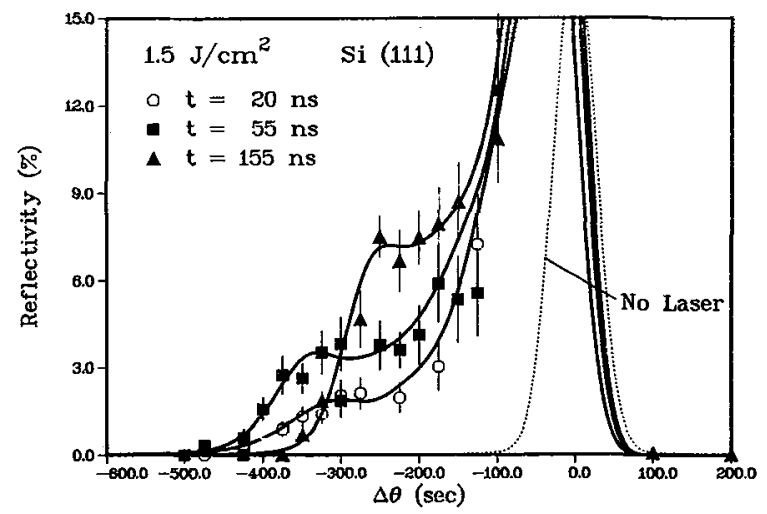

Fig. 5 - Time resolved $x$-ray scattering measured near the (111) Bragg reflection on (111) oriented silicon. From Ref. 13 . 


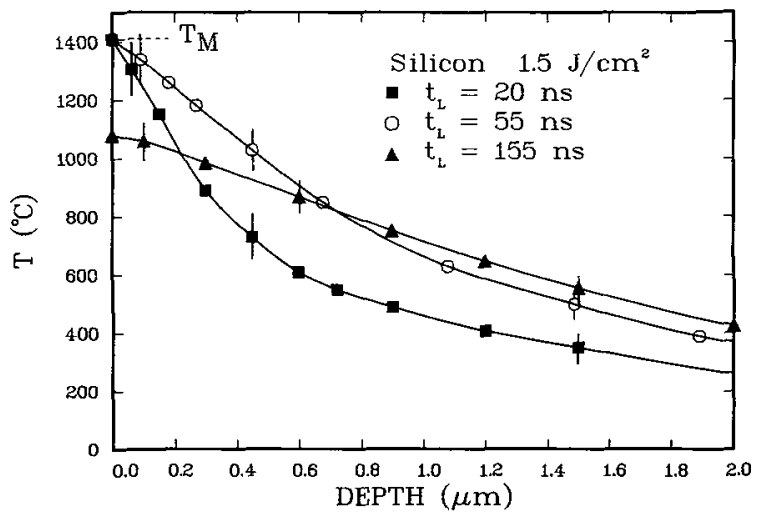

Fig. 6 - Temperature profiles in (111) silicon obtained by fitting $x$-ray scattering calculations to measurements shown in Fig. 5 . From Ref. 13.

temperature at $155 \mathrm{~ns}$ is less than the melting point and the thermal gradients are shallower than those at earlier times.

Results similar to those shown in Fig. 6 were obtained also using (100) silicon. Consequently the $x$-ray diffraction results clearly show that temperatures at or near the melting point are reached during pulsed-laser annealing, but interfacial undercooling during regrowth (or superheating of the solid during melting) must be less than $75^{\circ} \mathrm{C}$ for the laser conditions used. Faster growth velocities and/or more precise measurements of temperatures will be required to determine the interfacial undercooling during rapid solidification.

\section{VII - DOPANT INCORPORATION AT HIGH CONCENTRATIONS; MAXIMUM SUBSTITUTIONAL SOLUBILITIES (CMAX)}

As the dopant concentration increases, a maximum substitutional concentration (cmax) is reached above which the dopant is no longer incorporated into substitutional iattice sites for a given growth velocity /6/. Examples are shown in Fig. 7 for the case of 208pb in (100) and (111) $\mathrm{Si}$. Following laser annealing (ruby, $1.3 \mathrm{~J} / \mathrm{cm}^{2}$ ), RBS-ion channeling measurements were used to measured the total and substitutional

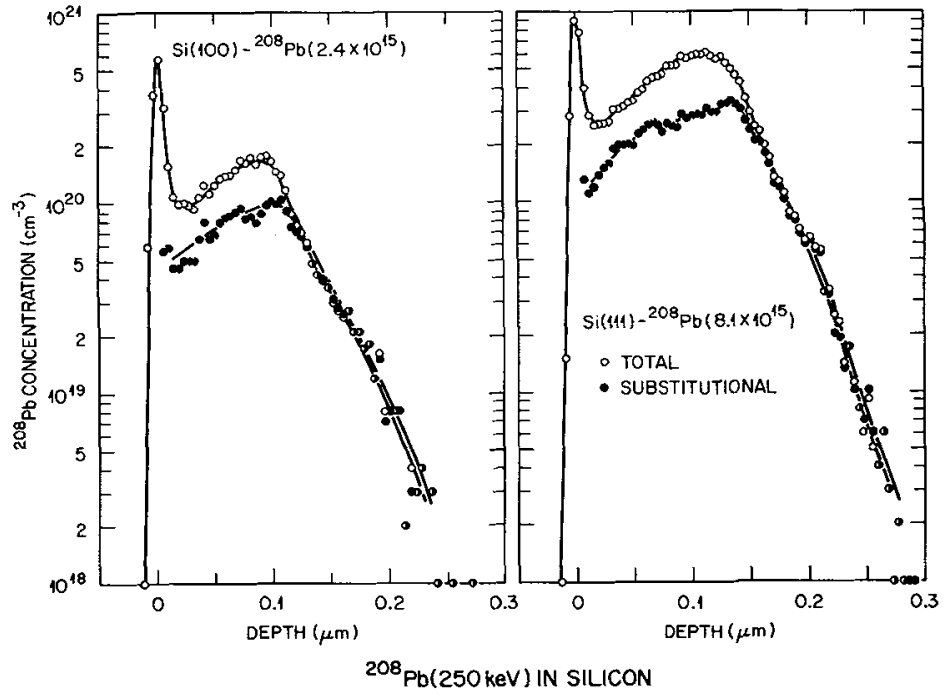

Fig. 7 - Limitations to the incorporation of $208 \mathrm{pb}$ into (100) and (111) silicon as a result of ruby laser annealing. Regrowth velocity is $\sim 4.5 \mathrm{~m} / \mathrm{s}$. 
TABLE II

Substitutional solubilties in silicon achieved by recrystallization at $4.5 \mathrm{~m} / \mathrm{s}$

\begin{tabular}{|c|c|c|c|c|}
\hline DOPANT & $C_{s}^{0}\left(\mathrm{~cm}^{-3}\right)$ & $\begin{array}{c}\mathrm{cmax}\left(\mathrm{cm}^{-3}\right) \\
(100) \mathrm{si}\end{array}$ & $\begin{array}{c}\mathrm{Cmax}_{\mathrm{Sax}}\left(\mathrm{cm}^{-3}\right) \\
(111) \mathrm{Si}\end{array}$ & COMMENT \\
\hline $\begin{array}{l}\mathrm{As} \\
\mathrm{Sb} \\
\mathrm{Bi}\end{array}$ & $\begin{array}{l}1.5 \times 10^{21} \\
7.0 \times 10^{19} \\
8.0 \times 10^{17}\end{array}$ & $\begin{array}{l}6.0 \times 10^{21} \\
2.0 \times 10^{21} \\
4.0 \times 10^{20}\end{array}$ & $\begin{array}{l}6.0 \times 10^{21} \\
2.0 \times 10^{21} \\
8.6 \times 10^{20}\end{array}$ & $\begin{array}{l}\text { Thermodynamic limit } \\
\text { Cell formation } \\
\text { Precipitation } \\
\text { Cell formation }\end{array}$ \\
\hline $\mathrm{Ge}$ & $5.0 \times 10^{22}$ & $6.0 \times 10^{21}$ & $>1.2 \times 10^{22}$ & \multirow{2}{*}{$\begin{array}{l}\text { Cell formation on } \\
(100) \text { formation } \\
\text { Cell formation } \\
\text { Precipitation } \\
\text { Cell formation }\end{array}$} \\
\hline $\begin{array}{l}\mathrm{Sn} \\
\mathrm{Pb}\end{array}$ & $5.5 \times 10^{19}$ & $\begin{array}{l}9.8 \times 10^{20} \\
1.0 \times 10^{20}\end{array}$ & $\begin{array}{l}1.4 \times 10^{21} \\
3.0 \times 10^{20}\end{array}$ & \\
\hline $\begin{array}{l}B \\
G a \\
\text { In } \\
\text { TI }\end{array}$ & $\begin{array}{l}6.0 \times 10^{20} \\
4.5 \times 10^{19} \\
8.0 \times 10^{17} \\
--\end{array}$ & $\begin{array}{l}2.0 \times 10^{21} \\
4.5 \times 10^{20} \\
1.5 \times 10^{20} \\
-\end{array}$ & $\begin{array}{c}2.0 \times 10^{21} \\
7.2 \times 10^{20} \\
4.5 \times 10^{20} \\
---\end{array}$ & $\begin{array}{l}\text { Mechanical strain } \\
\text { Cell formation } \\
\text { Cell formation } \\
\text { Coherent precipita- } \\
\text { tion }\end{array}$ \\
\hline
\end{tabular}

concentrations as a function of depth. Up to a concentration of $\sim 1 \times 10^{20}$ for (100) Si and $3 \times 10^{20}$ for (111) Si the total and substitutional concentrations are indistinguishable. In the near surface region where the concentration exceeds these values, the total and substitutional concentrations differ considerably. These values are the maximum substitutional concentrations (cmax) which can be incorporated into $(100)$ and (111) $\mathrm{Si}$ at this growth velocity $(? 4.5 \mathrm{~m} / \mathrm{s})$. Values for Cmax have been determined /9/ for nine Group III, IV, or $V$ impurities in both (100) and (111) silicon at a growth velocity of $4.5 \mathrm{~m} / \mathrm{s}$. The results are summarized in Table II and compared with equilibrium solubility limits. The last column in Table II indicates the mechanism that limits substitutional solubility. These mechanisms are discussed in the next section.

VIII - LIMITATIONS TO SOLUBILITY

Substitutional solubility appears to be limited by four mechanisms $/ 9 /$. These are (1) thermodynamic limitations, (2) lattice strain, (3) interface instability during regrowth and (4) dopant precipitation in the liquid. Predictions of thermodynamic limits to dopant incorporation in silicon have been made by Cahn /21/. The basic idea is that the solidus and liquidus lines intersect at one point on the Gibbs free energy diagram. This limits the solid composition which can be formed from the liquid since there is no barrier to nucleation of the solid phase. The locus of these points piotted on the phase diagram defines the $T_{0}$ curve which is the limit to dopant incorporation even at infinite growth velocity.

Substitutional solubilities achieved during laser annealing are much higher than equilibrium solubility 1 imits $/ 6 /$, but in only one case do we appear to have reached Cahn's predicted limits. For the case of As in $\mathrm{Si}$, the value measured for $\mathrm{Cmax}_{\mathrm{S}}$ is independent of velcoity in the range of 2 to $6 \mathrm{~m} / \mathrm{s}$ and is independent of crystal orientation. Figure 8 shows results for $X e C 1$ laser annealing $(6 \mathrm{~m} / \mathrm{s})$ for high dose implants of $75_{\mathrm{As}}$ into (100) and (111) $\mathrm{Si}$. In each crystal, As is measured to be substitutional up to a concentration of $6 \times 10^{21} / \mathrm{cm}^{3}$. Above this concentration epitaxial growth stops and the near-surface region is observed by TEM to contain polycryst,alline regions, small amorphous regions and As precipitates. The line of demarkation between the epitaxially recrystallized region and the defective region is quite sharp. Based on the fact that this limit is independent of velocity and crystal orientation we conclude that the thermodynamic limit has been reached. 


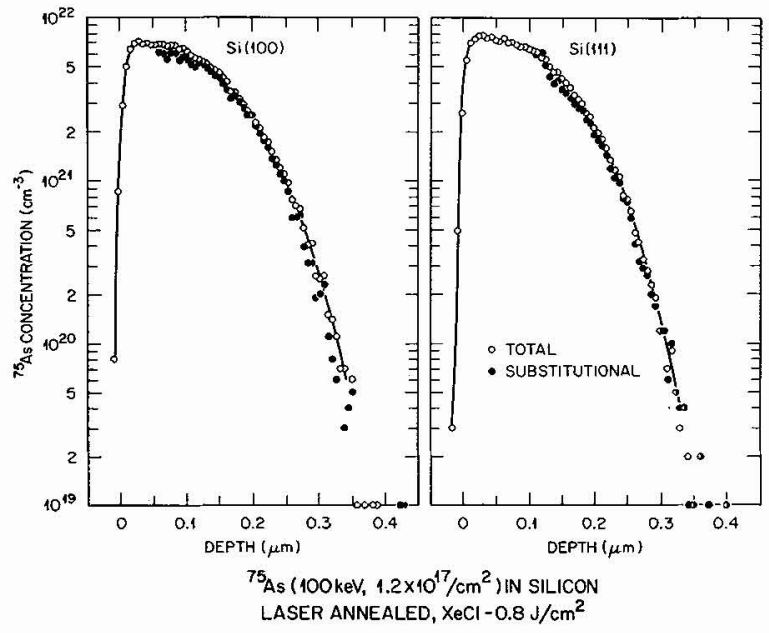

Fig. 8 - Limitations to the incorporation of As in (100) and (111) silicon as a result of laser annealing. Regrowth velocity is $\sim 6.0 \mathrm{~m} / \mathrm{s}$. From Ref. 9 .

For the case of $\mathrm{B}$ in $\mathrm{Si}$, strain in the implanted region after laser annealing provides the limit to dopant incorporation $/ 16 /$. The strain results from the one dimensional lattice concentration which occurs when $B$ is incorporated into the lattice during recrystallization $/ 22 \%$. When the strain exceeds the fracture strength, cracks will develop in the implanted region as shown in Fig. 9. The cracks are observed to be $\sim 1 \mu \mathrm{m}$ wide $\times 1 \mu \mathrm{m}$ deep and extend the entire length of the sample ( 1 $\mathrm{cm})$. Cracks will develop whenever the boron concentration exceeds $\rightarrow 4$ at.\%. At lower concentrations, the annealed region is strained but cracks do not develop.

Maximum substitutional solubilities for several impurities (Ga, In, Ge, Sn, Sb, Bi, and $\mathrm{Pb}$ ) are limited by interface instability which develops during regrowth. The instability leads to lateral segregation of the dopant into the walls of a cell structure in the near-surface region. An example is shown in Fig. 10 for the case of In in (100) Si. Up to a concentration of $1.5-2.0 \times 1020 / \mathrm{cm}^{3}$, the In is highly substitutional following laser annealing. Above this concentration the nonsubstitutional In is localized to the cell walls (Fig. 10 right) which penetrate to a depth of $21000 \AA$. Values determined for $k^{\prime}$ in the case of $\mathrm{Ga}$, in, $\mathrm{Ge}, \mathrm{Bi}$, and $\mathrm{Pb}$ are larger for (111) crystals than for the (100) case at equivalent growth velocities. The larger values for $k^{\prime}$ in (111) crystals imply that higher concentrations can be trapped into the solid before interface instability occurs. This accounts for the fact that $C_{s} \max$ is larger for these impurities in the (111) case.

A few of the impurities listed in Table II (Bi, $\mathrm{Pb}, \mathrm{Tl}$ ) are immiscible in liquid silicon. Consequently at low growth velocities these impurities will precipitate in the liquid if the time available for nucleation and growth of precipitates is long
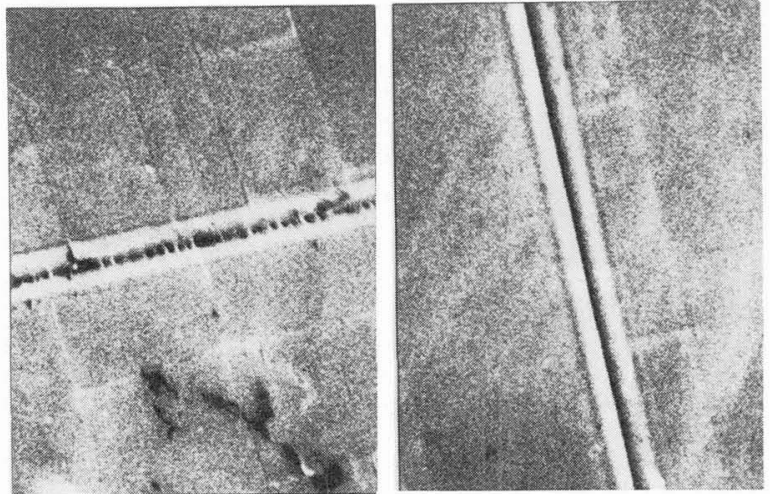

Fig. 9 - Cracks in the nearsurface region of boron implanted silicon following laser annealing. Ref. 16 . 


\section{CONCENTRATION PROFILE}

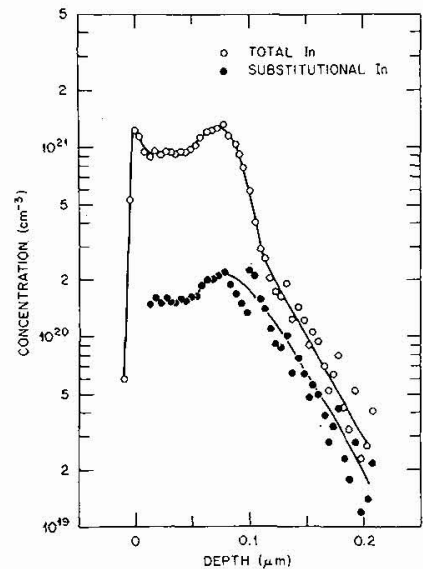

MICROSTRUCTURE
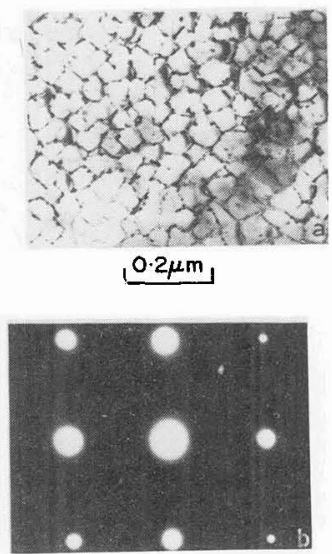

Fig. 10 - Profiles and microstructures for $115 \mathrm{In}\left(125 \mathrm{keV}, 1.3 \times 1016 / \mathrm{cm}^{2}\right)$ in (100) $\mathrm{Si}$ following ruby laser annealing. From Ref. 16.
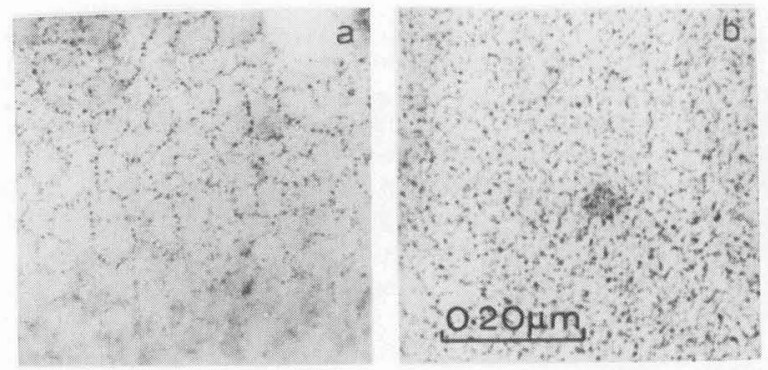

Fig. 11 - Microstructures in the near-surface region of $(100) \mathrm{Si}$ implanted by $209_{\mathrm{Bi}}(250 \mathrm{KeV}, 1.4 \times$ $\left.1016 / \mathrm{cm}^{2}\right)$ and ruby laser annealed to give rise to growth velocities of (a) $1.5 \mathrm{~m} / \mathrm{s}$ and (b) $0.7 \mathrm{~m} / \mathrm{s}$. From Ref. 8 .

enough. Precipitates formed in the liquid will be frozen into the solid during solidification. Figure 11 shows this for $B i$ in silicon at growth velocities of 1.5 $\mathrm{m} / \mathrm{s}$ (11a) and $0.7 \mathrm{~m} / \mathrm{s}$ (11b). At the lower growth velocity the annealed region contains a uniform dispersion of precipitates. At the high velocity a cell structure is observed, with the walls being decorated by precipitates. At velocities greater than $3 \mathrm{~m} / \mathrm{s}$ only the cell structure is observed with little or no indication of precipitates. The value of $\mathrm{K}^{\prime}$ for $\mathrm{Bi}, \mathrm{Pb}$, and $\mathrm{Tl}$ is less than unity and each is immiscible in liquid $S i$. Consequently at low growth velocities, dopant precipitation will limit substitutional solubility but at higher velocities interface instability will dominate.

\section{IX - MELTING OF THIN LAYERS OF AMORPHOUS SILICON}

Preliminary measurements show that the threshold energy required to melt the surface of an amorphous film is much less than that required to melt crystalline silicon /26/. An example is shown in Fig. 12. The melt depth in the amorphous layer was determined using TEM to measure the thickness of the polycrystalline layer after laser annealing a $5100 \AA$ film of amorphous silicon on a single crystal substrate. (The amorphous layer was formed by $28 \mathrm{Si}^{+}-200 \mathrm{KeV}$ implantation at $\mathrm{LN}_{2}$.) The melt depth in crystalline silicon was determined from TEM measurements of the depth of the splitting of dislocations after laser annealing a crystalline sample containing dislocation loops /24/. Laser annealing was carried out using a XeCl laser, 0.308 $\mu m$ wavelength. At this wavelength the absorption coefficient even in crystalline silicon is $210^{6} \mathrm{~cm}^{-1}$ and the light will be absorbed in $2100 \AA$. As shown by the preliminary data in Fig. 12, the threshold energy required to melt the surface of the amorphous film $\left(20.2 \mathrm{~J} / \mathrm{cm}^{2}\right)$ is much less than that required to melt the surface of 


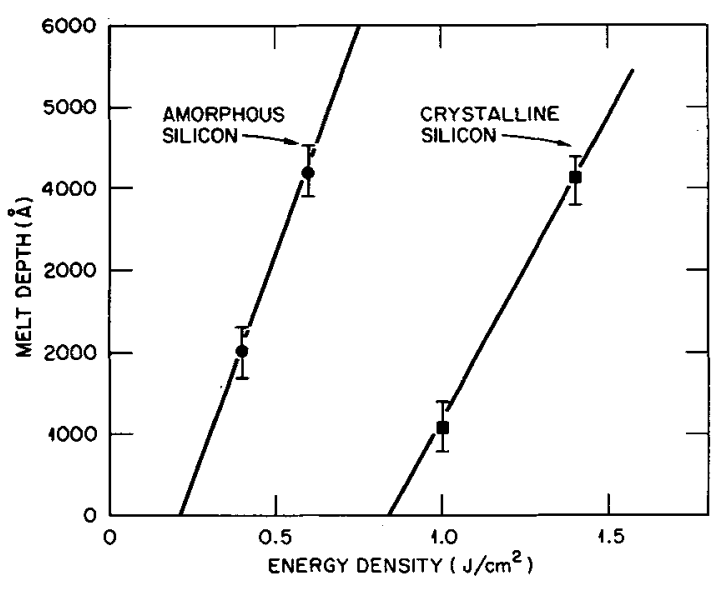

MELTING OF SILICON BY XOCI LASER ( $3080 \AA, 30 \times 10^{-9} \mathrm{sec}$ )
Fig. 12 - Depth of melting in crystalline and amorphous silicon resulting from $\mathrm{XeCl}$ laser irradiation. In the amorphous case, the amorphous layer was $0.51 \mu \mathrm{m}$ thick and was created by $28 \mathrm{Si}^{+}$ (200 KeV) implantation at liquid nitrogen temperature.

crystalline silicon $\left(0.8 \mathrm{~J} / \mathrm{cm}^{2}\right)$. The large differences in threshold energy can only be accounted for partially by reported differences in the melting temperatures of amorphous and crystalline silicon /25/. The anomously low threshold energy for melting the surface of amorphous silicon may indicate that the thermal conductivity of amorphous silicon is substantially lower than that of crystalline silicon. Values for the thermal conductivity of amorphous silicon are not available, but all heat flow calculations reported to date have assumed that the thermal conductivity of amorphous silicon is the same as that of crystalline silicon. More extensive measurements of the type shown in Fig. 12 will be needed to resolve this point, but this information is essential if accurate heat flow calculations are to be performed for the case of amorphous layers on crystalline substrates.

\section{REFERENCES}

1. Laser-Solid Interactions and Laser Processing-1978, (ed. by S. D. Ferris, H. J. Leamy and J. M. Poate, American Institute of Physics, New York), 1979.

2. Laser and Electron Beam Processing of Materials, (ed. by C. W. White and P. S. Peercy, Academic Press, New York), 1980.

3. Laser and Electron-Beam Solid Interactions and Materials Processing, (ed. by J. F. Gibbons, L. D. Hess and T. W. Sigmon, North Holland, New York), 1981.

4. Laser and Electron Beam Interactions with Solids, (ed. by B. R. Appleton and G. K. Celler, North Holl and, New York), 1982.

5. Laser-Sol id Interactions and Transient Thermal Processing of Solids, (ed. by $\mathrm{J}$. Narayan, W. L. Brown, and R. A. Lemons, North Holland, New York), in press.

6. WHITE C.W., WILSON S.R., APPLETON B.R., and YOUNG F.W., J. Appl. Phys. 51 (1980) 738 .

7. STUCK R., FOGARASSY E., GROB J.J., and SIFFERT P., Appl. Phys. 23 (1980) 15. (1980).

8. WHITE C.W., Ref. 4, p. 109.

9. WHITE C.W., ZEHNER D.M., NARAYAN J., HOLLAND, 0.W., and APPLETON B.R., Ref. 5, p. 287.

10. FOGARASSY E., STUCK R., SIFFERT P., BROUTET F., and DESOYER J.C., Ref. 5, p. 311.

11. GALVIN G.J., THOMPSON M.0., MAYER J.W., HAMMOND R.B., PAULTER N., and PEERCY P.S., Phys. Rev. Lett. 48 (1982) 33.

12. LARSON B.C., WHITE C.W., NOGGLE T.S., and MILLS, D.M., Phys. Rev. Lett. 48 (1982) 337 . 
13. LARSON B.C., WHITE C.W., NOGGLE T.S., BARHORST J.F., and MILLS D.M., App I. Phys. Lett. 42 (1982) 282.

14. CULLIS A.G., WEBBER H.C., POATE J.M., and SIMONS A.L., Appl. Phys. Lett. $\underline{36}$ (1980) 320.

15. BAERI P., POATE J.M., CAMPISANO S.U., FOTI G., RIMINI E., and CULLIS A.G., App1. Phys. Lett. 37 (1981) 912.

16. WHITE C.W., APPLETON B.R., STRITZKER B., ZEHNER D.M., and WILSON S.R., Ref. 3, p. 109 .

17. POATE J.M., Ref. 4 , p. 121 .

18. BAERI P., FOTI G., POATE J.M., CAMPISANO S.U., and CULLIS A.G., Appr. Phys. Lett. 38 (1981) 800 .

19. GILMER G.H., Ref. 5 , p. 249

20. SPAEPEN F. and TURNBULL D., p. 15 in Laser Annealing of Semiconductors, ed. by J. M. Poate and J. W. Mayer, Academic Press, New York, 1982.

21. CAHN J.W., CORIELL S.R., and BOETTINGER W.J., Ref. 2, p. 89.

22. LARSON B.C., WHITE C.W., and APPLETON B.R., AppT. Phys. Lett. 32 (1978) 801.

23. NARAYAN J., J. Appl. Phys. 52 (1981) 1289.

24. NARAYAN J., and WHITE C.W., Ref. 2, p. 65.

25. BAERI P., FOTI G., POATE J.M., and CULLIS A.G., Phys. Rev. Lett. 45 (1980) 2036.

26. NARAYAN J. and WHITE C.W., to be published. 